\title{
STUDYING CONDITIONS AND PROBLEMS FOR DEVELOPING MATHEMATICS LEARNING MODEL OF UNDERGRADUATE STUDENTS IN THAILAND
}

\author{
Puchong Praekhaow $^{* 1,2}$, Tweesak Chindanurak ${ }^{3}$, Sureerat Areeraksakul Konglok ${ }^{3}$, \\ Kritsana Sokhuma ${ }^{4}$ \\ ${ }^{1}$ Doctor of Philosophy in Education, Sukhothai Thammathirat Open University, Thailand \\ ${ }^{2}$ King Mongkut's University of Technology Thonburi, Thailand \\ ${ }^{3}$ Sukhothai Thammathirat Open University, Thailand \\ ${ }^{4}$ Phranakhon Rajabhat University, Thailand
}

\section{Article Info \\ Article history: \\ Received Jan 8, 2021 \\ Revised Jan 22, 2021 \\ Accepted Jan 27, 2021}

\section{Keywords:}

Factor Analysis,

Mathematics Learning Model,

Regression Analysis

\begin{abstract}
This research intends to study the conditions and problems of learning management in Mathematics for undergraduate students. Research problem is that students have low achievement and ability problem-solving in mathematics. The research method used is development through the stages of conducting preliminary studies and quantitative survey research, producing initial designs of integrative learning models. The results of this research were used to develop the mathematics learning model. The research was conducted over a one-year period considering two groups. The first sample was collected from the group with 376 students studying mathematics in the academic year 2020. The second sample was collected from the group with 116 professors of public universities in Thailand. Questionnaires were used as a tool of the research. The data analysis was divided into 2 stages. The first stage was to analyze supporting factors with factor analysis. The second stage was to design the learning management of students and professors with regression analysis. The results have shown that the opinions of students and professors on conditions and problems of learning management can be summarized as follows: (1) The students' opinions for corrections in the aspects were group learning and teamwork, steps of solving problems, a learning model that is real situations, and the problem-based learning, respectively. (2) The professors' opinions for corrections in the aspects were student interaction, academic achievement, problem-based learning, and learning management model that is current situations, respectively. (3) The supporting factors for the development of the learning management model that professors and students were consistent in solving problems. It was found that there were three main factors as follows; group learning, problem-based learning, and active learning. The learning management model should be developed by integrating group learning, problem-based learning, and step of mathematical problem-solving to enhance problem-solving ability and mathematics learning achievement.
\end{abstract}

Copyright $(2021$ IKIP Siliwangi. All rights reserved.

\section{Corresponding Author:}

Puchong Praekhaow,

Department of Mathematics,

King Mongkut's University of Technology Thonburi,

126 Pracha Uthit Rd., Bang Mod, Thung Khru, Bangkok 10140, Thailand.

Email: puchong.pra@kmutt.ac.th

\section{How to Cite:}

Praekhaow, P., Chindanurak, T., Konglok, S. A., \& Sokhuma, K. (2021). Studying conditions and problems for developing mathematics learning model of undergraduate students in Thailand. Infinity, 10(1), 121-132. 


\section{INTRODUCTION}

Nowadays, all countries are at the beginning of the 21 st century. The conditions and problems on learning management in higher education need to be adjusted and review in order to solve the problems that arise. Some of these findings indicate that the achievement and problem-solving ability of students in Thailand is low. The research report on graduate employment in the academic year 2015 of King Mongkut's university of Technology Thonburi found the five problems of graduates as follows, working together with colleagues, socializing, problem solving, applications in work, ethics, and human relations (Temsiripot, 2015). The results of students' mathematical ability test when they first entered King Mongkut's university of Technology Thonburi at the bachelor's degree level for the academic year 2017. It was shown that students had problems with low mathematical achievement. They had an average score of 15.72 points out of 54, and there was 21.11 percent of students whom have to study general mathematics (Predasawat, 2017), corresponds to the mathematics exam results in the past three years. The students failed examinations in the mathematics since $2014-2016,10.12 \%, 13.05 \%$, and $14.59 \%$, respectively. In one academic year, approximately 2000 students are required to enroll in general mathematics. These problems are caused by learning management.

Based on the above information, the student's problems were mathematical achievement and ability to solve mathematical problems, which was a national student's problem. This issue is presented as the main topic of research in the Thailand educational development plan 2017-2032 (Office of the Education Council, 2017). This problem is a global problem in the world of education, especially for students in schools and college students and graduates with problem-solving abilities (Harisman et al., 2020; Hutajulu et al., 2019; Maharani et al., 2019). Robert King wrote in the Student Handbook for 21st Century Learning that new problem solving involves solving mathematical problems. Problem solving consists of critical thinking, creative thinking, collaboration, and communication (King, 2018). These things can be achieved through working together as a brainstorming group to define a problem, analyze the problem, then plan to find the answer, bring relevant knowledge together to develop problem solving and evaluation modes as shown in Figure 1.

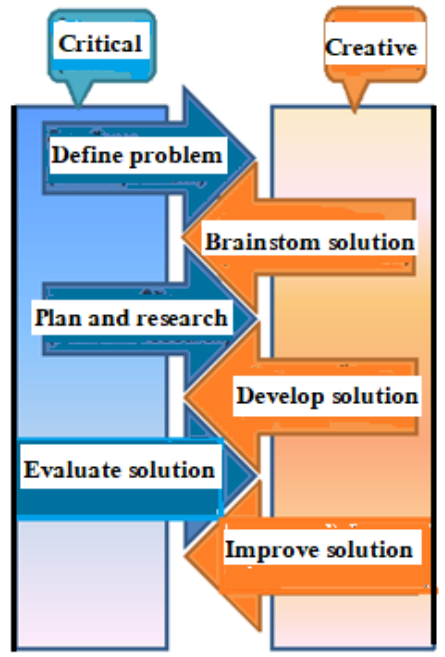

Figure 1. Steps of troubleshooting

Figure 1 shows that in line with the national education association and partnership for the 21 st century skills, $3 \mathrm{R}+4 \mathrm{C}$ is defined the core elements of the 21 st century learning 
framework, where mathematics is one of the 3R subjects (Phanich, 2012). Because of creative thinking, logical thinking, and problem analysis, this can be made in humans to help in solving the problems, forecast, plan, make decisions and apply them in daily life. It is also a tool on improving the quality of life (Ministry of education, 2017).

The problems of higher education in Thailand and abroad were presented to higher education institutions. It is needed to initiate the learning process that can train students' problem-solving skills, especially at mathematics in university, one of which is the integrative learning model. To find a new learning management model that can solve current conditions, researchers agree that we should develop a learning management model in mathematics. The advantages of developing a learning management model in mathematics are to enhance problem-solving ability and mathematics learning achievement. The conditions and problems of learning management in the mathematics should be studied on the first thing, in accordance with the concepts and principles of the systematic model development that consisting of 1) Analysis, 2) Design, 3) Develop, 4) Implement, and 5) Evaluate (Dick, Carey, \& Carey, 2005). Therefore, the first thing that researchers should be interested in is developing a learning management model. Study the conditions and problems of mathematics learning management of the undergraduate level. Because that study from student and professors' perspectives are challenges in mathematics learning.The research question is what the students and professors want to solve in learning management of mathematics. we can define it a modern and visible learning management. By studying the conditions and problems of mathematics learning management of undergraduate students to propose a guideline for the development of learning management model in mathematics courses for the university.

\section{METHOD}

This research study was based on the methodology of quantitative survey research. The survey was conducted to observe the learning of mathematics which has been carried out by professors, and questionnaires also conducted to these students and professors so that it is known what learning deficiencies must be improved. The resulting data for each problem was analyzed using R-Studio software to find the results. Those composed of the details were as follow:

\subsection{Population and sample}

The research population consists of two parts. First, the population was 6,178 undergraduate students of studying mathematics at the Faculty of Engineering in Thailand. Second, Population was 164 professors of mathematics department in public universities.

The samples of students and professors were selected by stratified sampling that the stratums are Bangkok and region of Thailand. The sample size was calculated by Taro Yamane formula, with the sampling error can occur not more than 5\% and then divided in equal proportions as follows. First, 379 undergraduate students were selected by sampling from the Faculty of Engineering in Thailand. Second, 116 professors were selected by sampling from mathematics department in public universities of Thailand.

\subsection{Research variables and study duration}

The independent variables in this research are conditions and problems of mathematics learning management in university, and for the dependent variables consisted of the problem level of mathematics learning management in each area. The period of study is the 2020 academic year. 


\subsection{Research instruments}

The research instrument had two parts. First, part A was the background information of the respondents who were the students and professors. Second, part B was the student and professors' questionnaires of learning management in mathematics were constructed by using problem situations at present with rubric scoring for assessment. The 15 questions of questionnaire were in the format of Likert rating scale 5 levels, where the quality of the questionnaires had been evaluated by relevant experts and try-out in the 30 students. The Item-Objective Congruence (IOC) was used to evaluate the items of the questionnaire based on the score range from -1 to +1 , congruent $=+1$, questionable $=0$ and incongruent $=-1$. The items that had scored lower than 0.5 were revised. On the other hand, the items that had scores higher than or equal to 0.5 were reserved. It was found that the index of item objective congruence (IOC) of questionnaires, each question was in the range of $0.8-1.0$. The reliability value was calculated by using Cronbaches alpha to ensure whether there was internal consistency within the items. Mallery and George (2000) illustrated the value of Coefficient Cronbaches Alpha as the following: $\geq 0.9=$ Excellent, $\geq 0.8=$ Good, $\geq 0.7=$ Acceptable, $\geq 0.6=$ Questionable, $\geq 0.5=$ Poor, and $\leq 0.5=$ Unacceptable. Therefore, in order for the research questionnaire to be reliable, its value of Coefficient Cronbach ${ }^{\text {ee }}$ Alpha must be at least 0.7. According to the pre-test, the Cronbach's Alpha was found that the value of Cronbach's alpha coefficient was 0.821 for students' questionnaires and 0.812 for professors' questionnaires. It was shown that quality of all tools was more than the required criteria, so the questionnaire was highly reliable.

\subsection{Data collection}

The researcher made a request for permission to the mathematics department of the university that was randomly selected as the sample. The questionnaire was distributed to samples in the university. Student and Professor volunteers answered the questionnaire according to the volunteer's consent document of the Human Research Ethics Committee, King Mongkut's University of Technology Thonburi. Which has conducted the research project evaluation of the researcher and agreed. To pass the human research ethics assessment by certificate number KMUTT-IRB-COA-2020-025.

\subsection{Data analysis}

Calculate the mean of each question of the conditions and problems in the questionnaire. The mean is interpreted by the 5-level Likert Scale rating The Likert criteria. can be seen in the following Table 1 (Wongratana, 2017).

Table 1. The evaluation criteria for Likert scale

\begin{tabular}{cc}
\hline Score Interval (Mean) & Evaluation criteria \\
\hline $1.00-1.79$ & Very low level \\
$1.80-2.59$ & Low level \\
$2.60-3.39$ & Medium level \\
$3.40-4.19$ & High level \\
$4.20-5.00$ & Very high level \\
\hline
\end{tabular}

The conditions and problems of learning management in questionnaires were used to calculate the factor components by factor analysis. To summarize the problems and needs of students and professors in the development of learning management model. 


\section{RESULTS AND DISCUSSION}

\subsection{Results}

\subsubsection{Professors analysis results}

The analysis is shown on the Table 2 of the 15 questions from professors. It is found that the relevant study of the learning management problems to be solved of professors in mathematics, the results have shown that the vast majority of professors thought the current learning management problems at a high level (Mean $=3.51, \mathrm{SD} .=0.39)$. The problems that should be developed in the following order: helping each other in learning, low academic achievement, the learning management style is not for the current situation, interaction with peers and professors, and problem-based learning.

Table 2. The interpretation of the professor's effects on the conditions and problems

\begin{tabular}{|c|c|c|c|}
\hline Questions & Mean & SD & Interpretation \\
\hline 1. Teaching assessments have clear criteria & 4.41 & 0.79 & High \\
\hline 2. Questions are used to stimulate interest in teaching & 3.94 & 3.08 & High \\
\hline $\begin{array}{l}\text { 3. The learning outcome is clearly defined in the } \\
\text { learning objective }\end{array}$ & 3.88 & 1.05 & High \\
\hline 4. Learning are self-learning from the exercises & 3.82 & 0.63 & High \\
\hline 5. Your teaching approach is a lecture style & 3.76 & 0.56 & High \\
\hline $\begin{array}{l}\text { 6. Teaching mathematics should be solving problems } \\
\text { from real situations }\end{array}$ & 3.65 & 0.70 & High \\
\hline $\begin{array}{l}\text { 7. The learning style of the students lacked the search } \\
\text { for knowledge }\end{array}$ & 3.53 & 0.62 & High \\
\hline $\begin{array}{l}\text { 8. The professor's learning management model is } \\
\text { suitable for the current situation }\end{array}$ & 3.47 & 0.80 & High \\
\hline $\begin{array}{l}\text { 9. Your learning management style opens up } \\
\text { opportunities for interaction between learners }\end{array}$ & 3.47 & 0.71 & High \\
\hline $\begin{array}{l}\text { 10. Your learning management model is problem- } \\
\text { based learning }\end{array}$ & 3.29 & 0.84 & Medium \\
\hline $\begin{array}{l}\text { 11. Your students do not have a step-by-step solution } \\
\text { to math problems }\end{array}$ & 3.24 & 0.83 & Medium \\
\hline $\begin{array}{l}\text { 12. Your learning management style does not offer } \\
\text { group learning in classroom }\end{array}$ & 3.18 & 1.01 & Medium \\
\hline 13. My students have low academic achievement & 3.12 & 0.85 & Medium \\
\hline $\begin{array}{l}\text { 14. Your teaching does not offer solutions by students } \\
\text { in the classroom }\end{array}$ & 3.12 & 1.16 & Medium \\
\hline 15. Your students lack mutual assistance in learning & 2.82 & 0.80 & Medium \\
\hline Tota & 3.51 & 0.39 & High \\
\hline
\end{tabular}

\subsubsection{Students analysis results}

The analysis shown on the Table 3 of the 15 questions from students. It is found that the relevant study of the learning management problems to be solved of students in mathematics, the results have shown that the vast majority of students thought the current 
learning management problems at medium level. $($ Mean $=3.30, \mathrm{SD} .=0.34)$ The problems that should be developed in the following order: team collaboration, experience in the presentation, steps of solving math problems, the unsuitable learning management style for the current situation, interaction with peers and professors, and problem-based learning.

Table 3. The interpretation of the student's effects on the conditions and problems

\begin{tabular}{|c|c|c|c|}
\hline Questions & Mean & SD & Interpretation \\
\hline $\begin{array}{l}\text { 1. Mathematics creates a curiosity and interest in problem } \\
\text { solving }\end{array}$ & 3.77 & 0.86 & High \\
\hline $\begin{array}{l}\text { 2. The students are trained to have a problem-solving process in } \\
\text { Mathematics }\end{array}$ & 3.70 & 0.84 & High \\
\hline 3. Mathematics focuses on solving mathematical problems & 3.66 & 0.80 & High \\
\hline $\begin{array}{l}\text { 4. Mathematics is a subject that taught me a lot of methodology } \\
\text { for solving problems }\end{array}$ & 3.58 & 0.94 & High \\
\hline 5. Mathematics is taught mostly by lectures & 3.55 & 0.91 & High \\
\hline 6. Mathematics is taught to build knowledge by students & 3.49 & 1.04 & High \\
\hline 7. Mathematics should provide to learn by solving problems & 3.43 & 0.95 & High \\
\hline $\begin{array}{l}\text { 8. Teaching mathematics should be interactive with peers and } \\
\text { professors }\end{array}$ & 3.34 & 0.91 & Medium \\
\hline 9. Mathematics is a subject that I can apply to in my daily life & 3.30 & 1.04 & Medium \\
\hline $\begin{array}{l}\text { 10. Mathematics gives students the opportunity to present their } \\
\text { work }\end{array}$ & 3.26 & 1.05 & Medium \\
\hline 11. Problem-based learning is used in mathematics teaching & 3.19 & 0.92 & Medium \\
\hline 12. I still lack the ability to solve math problems in mathematics & 2.83 & 0.97 & Medium \\
\hline 13. I still lack to do a well-structured in math subjective test & 2.83 & 0.99 & Medium \\
\hline $\begin{array}{l}\text { 14. Mathematics is a subject that trains learners to have } \\
\text { experience in presentations }\end{array}$ & 2.75 & 1.07 & Medium \\
\hline $\begin{array}{l}\text { 15. Mathematics is a subject that trains learners who know how to } \\
\text { work together in groups }\end{array}$ & 2.75 & 1.10 & Medium \\
\hline Total & 3.30 & 0.34 & Medium \\
\hline
\end{tabular}

\subsubsection{Factors to develop new learning management}

The main ideas to create a learning management model of professors were shown by analysis results in Table 4.

Table 4. The results of factor analysis of professors

\begin{tabular}{llccc}
\hline \multicolumn{1}{c}{ Factors } & $\begin{array}{c}\text { Question } \\
\text { number }\end{array}$ & Variance & $\begin{array}{c}\text { \% } \\
\text { Variance }\end{array}$ \\
\hline 1. Group learning and problem-based learning & $6,8,7,3,15$ & 4.47 & 29.81 \\
2. Stimulating interest and research & $5,4,1,9$ & 3.08 & 20.55 \\
3. Solving problems in mathematics & $14,13,12,2$ & 1.82 & 12.14 \\
\hline
\end{tabular}




\begin{tabular}{llccc}
\hline \multicolumn{1}{c}{ Factors } & $\begin{array}{c}\text { Question } \\
\text { number }\end{array}$ & Variance & $\begin{array}{c}\text { \% } \\
\text { Variance }\end{array}$ \\
\hline $\begin{array}{l}\text { 4. } \\
\text { Presentation and interaction with peers and } \\
\text { professors }\end{array}$ & 10,11 & 1.21 & 8.04 \\
\hline & Total & 15 & & 70.55 \\
\hline
\end{tabular}

$\mathrm{KMO}=0.50$, Bartlett's Test has p-value $<0.01$

From Table 4, Fifteen questions relating to reasons for learning management model were factor analyzed using principal component analysis with Varimax(orthogonal) rotation. The analysis yielded four factors explaining a total of $70.55 \%$ of the variance for the entre set of variables. Factor 1 was group learning and problem-based learning. This first factor explained $29.81 \%$ of the variance. The second factor was stimulating interest and research. This second factor explained $20.55 \%$ of the variance. The third factor was solving problems in mathematics. This third factor explained that, $12.14 \%$ of the variance. And the fourth factor was presentation and interaction with peers and professors. The variance explained by this factor was $8.041 \%$. The KMO (Kaisser-Meyer-Olkin Measure of Sampling Adequacy) was 0.50 and Bartlett's Test of Sphericity (p-value $<0.01$ ) both indicate that the set of variables are at least adequately related for factor analysis.

The main ideas to create a learning management model of students were shown by analysis results in Table 5 .

Table 5. The results of factor analysis of students

\begin{tabular}{llccc}
\hline \multicolumn{1}{c}{ Factors } & $\begin{array}{c}\text { Question } \\
\text { number }\end{array}$ & Variance & $\begin{array}{c}\text { \% } \\
\text { Variance }\end{array}$ \\
\hline 1. Group learning and problem-based learning & $9,11,12,5,14$ & 5.41 & 36.08 \\
2. Solving problems in mathematics & $4,3,7,8$ & 2.21 & 14.75 \\
3. Solving problems in real situations & $15,13,6,10$ & 1.43 & 9.54 \\
4. Learn from problem solving & 2,1 & 1.30 & 8.69 \\
\hline \multicolumn{2}{c}{ Total } & 15 & & 69.06
\end{tabular}

$\mathrm{KMO}=0.72$, Bartlett's Test has $\mathrm{p}$-value $<0.01$

Table 5 shows that fifteen questions relating to reasons for learning management model were factor analyzed using principal component analysis with Varimax (orthogonal) rotation. The analysis yields four factors explaining a total of $69.06 \%$ of the variance for the entre set of variables. Factor 1 was group learning and problem-based learning. This first factor explained $36.08 \%$ of the variance. The second factor was solving problems in mathematics. This second factor explained $14.75 \%$ of the variance. The third factor was solving problems in real situations. This third factor explained $9.54 \%$ of the variance. And the fourth factor was learned from problem solving. The variance explained by this factor was $8.69 \%$. The KMO (Kaisser-Meyer-Olkin Measure of Sampling Adequacy) was 0.72 and Bartlett's Test of Sphericity ( $p$-value $<0.01$ ) both indicate that the set of variables are at least adequately related for factor analysis.

The main ideas relationship between professors and students were used to develop mathematics learning management model from factor analysis. These are shown and confirmed by multiple regression analyzes in Table 6 and Table 7 . 
Table 6. The ANOVA calculation of professors

\begin{tabular}{|c|c|c|c|c|c|}
\hline Model & $\begin{array}{c}\text { Sum of } \\
\text { squares }\end{array}$ & df & $\begin{array}{c}\text { Mean } \\
\text { squares }\end{array}$ & $\mathbf{F}$ & Sig \\
\hline Regression & 6.729 & 4 & 1.682 & 117.378 & $<0.001$ \\
\hline Residual & 1.691 & 111 & 0.014 & & \\
\hline Total & 8.320 & 115 & & & \\
\hline
\end{tabular}

Adjusted R square $=0.802$, Durbin Watson $=1.31$

Table 6 shows that a multiple linear regression was calculated to predict Y (problem level of learning mathematics) based on independent factors (group learning and problembased learning, stimulating interest and research, solving problems in mathematics, and presentation and interaction with peers and professors). A significant regression equation was found $\left(\mathrm{F}_{(4,111)}=117.378, \mathrm{p}<0.001\right)$, with an $\mathrm{R}^{2}$ of 0.802 . The $\mathrm{p}$-values of $\mathrm{F}$ statistics for the coefficients indicate whether these relationships are statistically significant. The statistical significance indicates that changes in the independent variables correlate with shifts in the dependent variable. The R-squared is 0.802 . Therefore, the problem level of learning mathematics that the independent variables explain collectively equal $80.20 \%$.

Table 7. The ANOVA calculation of students

\begin{tabular}{lccccc}
\hline \multicolumn{1}{c}{ Model } & $\begin{array}{c}\text { Sum of } \\
\text { Squares }\end{array}$ & df & $\begin{array}{c}\text { Mean } \\
\text { squares }\end{array}$ & F & Sig \\
\hline Regression & 100.191 & 4 & 25.048 & 14338.79 & $<0.001$ \\
Residual & 0.646 & 370 & 0.002 & & \\
\hline Total & 100.838 & 374 & & & \\
\hline Adjul &
\end{tabular}

Adjusted R square $=0.894$, Durbin Watson $=1.882$

Table 7 shows that a multiple linear regression was calculated to predict $\mathrm{Y}$ (problem level of learning math) based on independent factors (group learning and problem-based learning, solving problems in mathematics, solving problems in real situations, and learn from problem solving). A significant regression equation was found $\left(\mathrm{F}_{(4,370)}=14338.79, \mathrm{p}<\right.$ 0.001 ), with an $\mathrm{R}^{2}$ of 0.894 . The $\mathrm{p}$-values of $\mathrm{F}$ statistics for the coefficients indicate whether these relationships are statistically significant. The statistical significance indicates that changes in the independent variables correlate with shifts in the dependent variable. The Rsquared is 0.894 . Therefore, the problem level of learning mathematics that the independent variables explain collectively equal $89.40 \%$.

Table 6 and Table 7 shows that the results of multiple regression analysis support the ideas of students and professors. There is consistency in the learning management problem that should be addressed by the new learning management model. The model should consist of the first elements being group learning and problem-based learning, the steps of problem solving in mathematics. These will be stimulated by questions, search, actions, presentation, and interaction with peers and professors.

\subsection{Discussion}

Levels of learning management problems for professors and undergraduate students. It appears that overall mathematics students had a medium level of satisfaction in mathematics learning management problems. While the professors were at a high level. That was, students need to adjust to conditions and problems more than professors. This was 
consistent with the students' academic achievement and math problem solving ability, which was the problems. These problems arise from lecture learning management. It is also consistent with the hypothesis that the conditions and problems of mathematics learning management of students greater than the professors. Because those students did not learn by practice themselves following the constructivist learning theory (Piaget, 2002) that states that the learners actively construct or make their own knowledge by engaging in activities in their surrounding environment and society; in accordance with the sociocultural theory (Eggen \& Kauch, 2011) that states that the learning of human beings occurs as a result of the exchange and comparison of one's own knowledge with those of the others in the society; in accordance with the pragmatism theory (Eggen \& Kauch, 2011) that states that students can learn from their own real experience in doing all activities; and in accordance with the cooperative learning theory (Johnson \& Johnson, 2009) and the multiple intelligences learning theory (Gardner \& Moran, 2006; Sener \& Çokçaliskan, 2018) that state that the group process of the groups that have members with different abilities and characteristics results in the cooperative relationship, competitive relationship, and each individual's independent working.

When considering the conditions and problems of mathematics learning management in various fields from the factor analysis found that there were interesting observations as follows: The professors and students would like to revise their learning management in the following areas of (1) Group learning and problem-based learning, (2) Steps of problemsolving, (3) Learning in real situations, and (4) Presentation and interaction with peers and professors. Thus, researchers seek for contextualized teaching situations, where the student's environment takes on greater relevance (Romero \& Gómez, 2014), and such educational model should offer students tools to understand and interpret the world around them (Hegedus et al., 2017; Valencia-Arias et al., 2019)

These research results are consistent with the concepts and principles of the $21 \mathrm{st}$ century. The skills are often referred to as the $3 \mathrm{Rs}+4 \mathrm{Cs}$, the $3 \mathrm{Rs}$ are reading, writing and arithmetic, the 4Cs are critical thinking and problem-solving; effective communication; collaboration and team building; and, creativity and innovation. Where mathematics is in the 3Rs of core components (Phanich, 2012). The reason that mathematics makes students creative think logically, work systematically, able to analyze problems, help to solve problems. It helps to predict events, plan, make decisions and apply them in daily life. It was also a tool for studying other sciences, improving the quality of life (Ministry of Education, 2017). It was consistent on issues that we should developed in the 21 st century. Those were essential for students and higher education graduates to solve new problems that have not been encountered by myself. Which the problem-solving ability in mathematics problem related to solving real-life problems (Griffin \& Care, 2014; Larson \& Miller, 2011; Saavedra \& Opfer, 2012).

The components of the learning management model were presented by professors and students based on the analysis results. Several learning theories support the concept of a new learning management model: Constructivism Theory (Piaget, 2002). Students can learn through social and environmental interactions in different ways. Sociocultural Theory, human learning is the result of exchanging knowledge and comparing one's thoughts with others. Pragmatism Theory (Eggen \& Kauch, 2011), students can learn from real experiences and activities. Theory of Cooperative or Collaborative Learning (Johnson \& Johnson, 2009), Group processes in subgroups with different members provide mutual assistance in learning, there is brainstorming within each group enabling the group members to see the problem solving approach and learn the steps of problem solving. 
The results of research concluded that the new learning management model as shown in Figure 2.

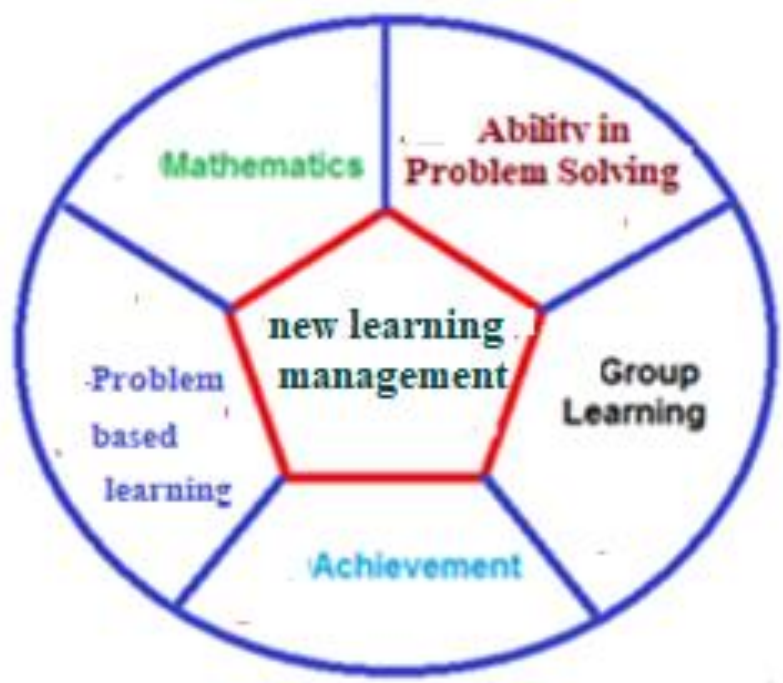

Figure 2. Components of a developed learning management model

Figure 2 shows the components of knowledge that will be integrated into the development of a learning management model in mathematics. The learning management model should be developed by integrating group learning, studying with problem-based learning and mathematical problem-solving, and enhancing problem-solving and mathematics learning achievement.

\section{CONCLUSION}

Based on research that has been done and discussion of research results, it can be seen that the instructors perceived the need for improvement for the lack of group learning and the lack of problem-based learning. While the students perceived that the instructors did not organize the learning management model that put emphasis on problem-based learning and group learning. Thus, it can be concluded that the instructors and students were in agreement on their needs for the learning management model with an emphasis on group learning, problem-based learning, learning based on thinking for problem-solving with the use of questions to motivate students to search for knowledge, and the classroom presentation for interaction with classmates. Developed learning management styles should arise from the integration of these elements.

\section{ACKNOWLEDGMENTS}

The authors would like to thank the human research ethics committee of King Mongkut's University of Technology Thonburi, which has considered the research project evaluation of the researcher and agreed. To pass the human research ethics assessment by certificate number KMUTT-IRB-COA-2020-025.

\section{REFERENCES}

Dick, W., Carey, L., \& Carey, J. O. (2005). The systematic design of instruction. London: Pearson. 
Eggen, P., \& Kauchak, D. (2011). Strategies and models for teachers: Teaching content and thinking skills. Pearson Higher Ed.

Gardner, H., \& Moran, S. (2006). The science of multiple intelligences theory: A response to Lynn Waterhouse. Educational psychologist, 41(4), 227-232. https://doi.org/10.1207/s15326985ep4104_2

Griffin, P., \& Care, E. (Eds.). (2014). Assessment and teaching of 21st century skills: Methods and approach. Springer. https://doi.org/10.1007/978-94-017-9395-7

Harisman, Y., Noto, M. S., \& Hidayat, W. (2020). Experience student background and their behavior in problem solving. Infinity Journal, 9(1), 59-68. https://doi.org/10.22460/infinity.v9i1.p59-68

Hegedus, S., Laborde, C., Brady, C., Dalton, S., Siller, H. S., Tabach, M., Trgalova, J., Moreno-Armella, L. (2017). Uses of technology in upper secondary mathematics education. Springer Nature. https://doi.org/10.1007/978-3-319-42611-2_1

Hutajulu, M., Wijaya, T. T., \& Hidayat, W. (2019). The effect of mathematical disposition and learning motivation on problem solving: an analysis. Infinity Journal, 8(2), 229238. https://doi.org/10.22460/infinity.v8i2.p229-238

Johnson, D. W., \& Johnson, R. T. (2009). An educational psychology success story: Social interdependence theory and cooperative learning. Educational researcher, 38(5), 365-379. https://doi.org/10.3102/0013189X09339057

King, R. (2018). What are the 21st-century skills?. Retrieved from https://k12.thoughtfullearning.com/FAQ/what-are-21st-century-skills

Larson, L. C., \& Miller, T. N. (2011). 21st century skills: Prepare students for the future. Kappa Delta Pi Record, 47(3), https://doi.org/10.1080/00228958.2011.10516575

Maharani, S., Kholid, M. N., Pradana, L. N., \& Nusantara, T. (2019). Problem solving in the context of computational thinking. Infinity Journal, 8(2), 109-116. https://doi.org/10.22460/infinity.v8i2.p109-116

Mallery, P., \& George, D. (2000). SPSS for windows step by step. Boston: Allyn \& Bacon.

Ministry of Education. (2017). Basic education core curriculum, B.E.2560. Bangkok: Teacher Sapa Publishing House.

Office of the Education Council. (2017). National education plan 2017-2036. Bangkok: Prikwan Graphic Co., Ltd.

Phanich, V. (2012). Methods for creating learning for students in the 21st century. Bangkok: Sodsri-Sarit Wongkis Foundation.

Piaget, J. (2002). Judgement and reasoning in the child. Abingdon: Routledge.

Predasawat, W. (2017). Report of mathematical proficiency test of first students enter the bachelor's degree KMUTT. Bangkok: Gifted Education office KMUTT.

Romero, L. R., \& Gómez, J. L. L. (2014). Competencias matemáticas desde una perspectiva curricular. Madrid: Alianza editorial.

Saavedra, A. R., \& Opfer, V. D. (2012). Learning 21st-century skills requires 21 st-century teaching. Phi Delta Kappan, 94(2), 8-13. https://doi.org/10.1177/003172171209400203 
Sener, S., \& Çokçaliskan, A. (2018). An investigation between multiple intelligences and learning styles. Journal of Education and Training Studies, 6(2), 125-132. https://doi.org/10.11114/jets.v6i2.2643

Temsiripot, W. (2015). Report on the monitoring of work and continuing education of graduates. Bangkok: Institutional research and Information unit KMUTT.

Valencia-Arias, A., Chalela-Naffah, S., \& Bermúdez-Hernández, J. (2019). A proposed model of e-learning tools acceptance among university students in developing countries. Education and Information Technologies, 24(2), 1057-1071. https://doi.org/10.1007/s10639-018-9815-2

Wongratana, C. (2017). Techniques for building research tools. Bangkok: Amon Publication. 